\title{
Multi-million dollar grants give 'Broadies' a lasting home
}

The Broad Institute of MIT and Harvard-a renowned genomics center based in Cambridge, Massachusetts-ended the first week in September with a clearer picture of its future and nearly half a billion dollars richer than it was at the start.

The windfall week began with an announcement on 2 September that the institute would receive \$86 million from the US National Institutes of Health for its molecular screening program, aimed at developing chemical probes for disease. But this news was overshadowed just two days later when Los Angeles philanthropists Eli and Edythe Broad announced a new $\$ 400$ million donation to the institute.

The Broads had already contributed $\$ 200$ million, but this initial donation stipulated that the funds had to be spent within ten years and could not be parlayed into a lasting endowment. Eli Broad, who calls himself a venture philanthropist, had initially viewed the institute as an experiment.

"We've been wondering for some time, 'what's going to happen at the end of that tenyear period?" says Eric Lander, the institute's founding director. "Will the experiment be over?"

The new donation will be funneled into a lasting endowment, enabling the institute to become an independent nonprofit. Harvard and the Massachusetts Institute of Technology (MIT) will continue to serve on its governing board, and collaborations will not be affected, Lander says.
The Broad Institute was launched in 2004 as an unusual attempt to unite several local academic powerhouses-MIT, the Whitehead Institute for Biomedical Research and Harvard University, all based in Cambridge-with the clinical expertise of Harvard's affiliated hospitals. In addition to more traditional scientific programs in topics ranging from infectious diseases to population genetics, the institute also has several research teams that focus on developing technological platforms, such as genome sequencing.

Over the past four years, the institute has swelled to include over 1,200 scientists and professional staff. Employees of the institutesometimes called 'Broadies' — often champion its collaborative atmosphere.

When cancer geneticist Tom Hudson was recently tasked with forming the Ontario Institute for Cancer Research in Toronto, which he now leads as president, he decided to adopt the Broad Institute's collaborative model. Bringing clinicians and researchers from different institutions together can be a challenge, he says, but the collaborative model also attracts funders interested in supporting translational research. "I'm being asked every week to go and give a talk somewhere," Hudson says, referring to his role in forming the Ontario institute. "There are a lot of groups looking at the Broad model."

Heidi Ledford, Cambridge, Massachusetts

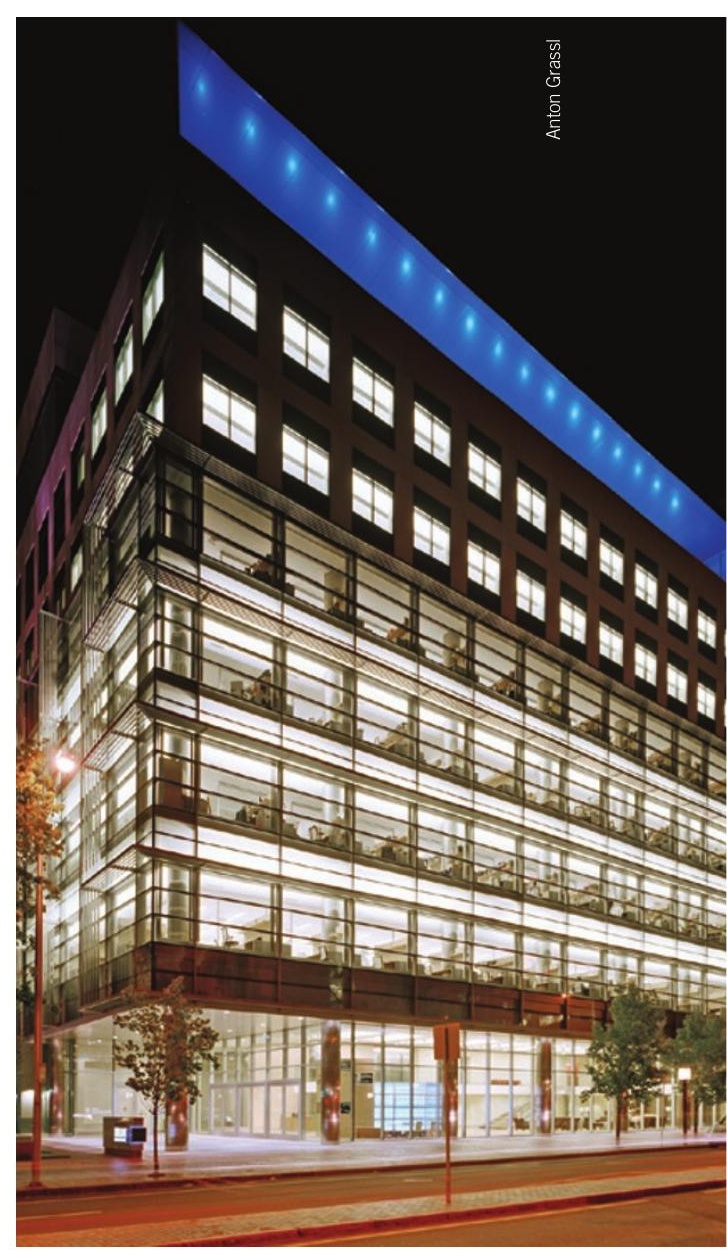

Here to stay: The institute looks forward

\section{Barriers set up to protect genome databases}

Policymakers have made swift changes to protect the US National Institutes of Health (NIH)'s large genetic databases, shifting from open to controlled access. The change comes in response to a study detailing a statistical method that makes it possible to identify individual DNA profiles within a mixture of pooled genetic data from more than 1,000 people (PLoS Genet., doi:10.1371/journal. pgen.1000167; 2008). Researchers wanting access must now apply for permission through a web-based request system, which requires approvals from their institutions as well as the $\mathrm{NIH}-\mathrm{a}$ process that could take up to three weeks.

Rather than withdrawing the pooled information from its databases, the NIH policymakers have decided to treat it with the same precautions as an individual's data. "The goal is not to hamper research, and this shift from open to controlled access may alter a researcher's timeline slightly, but probably not in a major way because we're using an existing policy and system," says Laura Lyman Rodriguez, acting director for the Office of Policy, Communications and Education at the NIH.

David Craig, an investigator at the Translational Genomics
Research Institute in Phoenix, Arizona and senior author of the study that triggered the data access change, doesn't think the new hurdles will affect how researchers collaborate. "Actually, what I hope comes out of this is an effort to share more individual-level data," he says. "The open sharing of aggregate data as required by [genome-wide association studies] has become a crutch and prevents us from making bigger discoveries [...] because we have to look at one gene at time."

Craig cites a recent study of prostate cancer (N. Engl. J. Med. $358,910-919 ; 2008$ ) that found a combined association of gene variants across five chromosomal regions influences risk of this disease. According to Craig, this kind of result is only achievable if researchers can compare individual genotype data from more than one gene variant at a time, which is only possible with individual, not aggregate, data.

In January 2008, an NIH policy for genome-wide association studies went into effect, mandating that investigators funded by the NIH submit de-identified genetic data to a centralized repository. Genevive Bjorn, Maui, Hawaii 